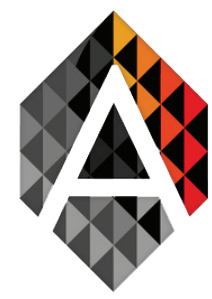

\title{
A Review on Blockchain's Applications and Implementations
}

\section{Pervez Ahmad ${ }^{\mathrm{a}}$, Muhammad Ahmad ${ }^{\mathrm{b}}$, Usman Ahmed $\operatorname{Raza}^{\mathrm{c}}$}

a Department of Computer Science \& Information Technology, Lahore Leads University, Lahore, Pakistan

b Department of Computer Science \& Information Technology, Lahore Leads University, Lahore, Pakistan

c Department of Computer Science \& Information Technology, Lahore Leads University, Lahore, Pakistan

pervezleads@gmail.com; muhammadahmadnazar@gmail.com; usmanahmedraza@gmail. com

\begin{tabular}{ll} 
KEYWORDS & ABSTRACT \\
\hline Blockchain; & Blockchain Technology (BCT) is one of many other emerging technologies that \\
Artificial & were introduced in the past several years \& carried loads of potential utilizing \\
Intelligence; & technological development. This paper describes in detail the progress made in \\
Internet of & Blockchain Technology. Keeping this in mind, some fields have been determined \\
Things (IoT); & in which their efficiency and modernization can be promoted by using Blockchain \\
Peer to Peer & Technology. It also describes the problems and challenges faced in implementing \\
(P2P) Network; & Blockchain Technology. Researchers are performing studies vigorously to \\
Distributed & discover all the possible proficiencies of Blockchain Technology with some of \\
Networks & them having faith in the Blockchain being vital for a de-centralized civilization. \\
& This paper provides an overview of Blockchain's applications.
\end{tabular}

\section{Introduction}

Blockchain Technology is one of many other emerging technologies that were introduced in the past several years \& carried loads of potential utilizing technological development. The study is still going on for finding complete abilities of Blockchain Technology and implementing it to the full extent. Some of the researchers accept it as true that Blockchain Technology is vital for the creation of a decentralized civilization contrary to our present society which is fully centralized and is being run by only a few people (Kaushik et al., 2017). For instance, the whole economy is being run by the

Pervez Ahmad, Muhammad Ahmad, Usman Ahmed Raza

A Review on Blockchain's Applications and Implementations
ADCAIJ: Advances in Distributed Computing and Artificial Intelligence Journal Regular Issue, Vol. 10 N. 2 (2021), 197-208 eISSN: 2255-2863 - https://adcaij.usal.es Ediciones Universidad de Salamanca - CC BY-NC-ND 
official government-approved banks and institutions where only a small number of people of the panel have the authority to make decisions including larger companies such as Google or Facebook, having billions of customers on average make us see what they want to (Kaushik et al., 2017).

On the other hand, a decentralized society is where the authority of decisions is not limited to only a small number of people but all associates of that system have the power to decide. Cryptocurrency, such as Bitcoin can be quoted as the best example of a decentralized system that does not involve any middleman or any bank to fulfill the transactions. In this system, each party can surely see its transaction which is also being recorded in a digital ledger through Blockchain Technology making it easy to find the history of all of their transactions back to the primary source (Pilkington et al., 2016).

The fundamental structure is operated by three layers which are named the Network Layer, Application layer \& the Data Link Layer as following (Figure 1). The first Application Layer has many of the applications which provide an interface to use Blockchain \& its implementations such as digital agreements or cryptocurrencies. The data layers include and form blocks or nodes in Blockchain which have all the operations, algorithms such as Hash Pointer or digital signatures which make this technology de-centralized and clear. The last or the Network Layer uses internet protocol \& peer-to-peer network which decentralizes the whole system and makes way for the Blockchain in connecting and interacting with the users and with surroundings. The Blockchain reaches consensus in this layer which is the most significant job in this system. The survey paper will deliberate Blockchain Technology and also its applications to some extent (Pilkington et al., 2016).

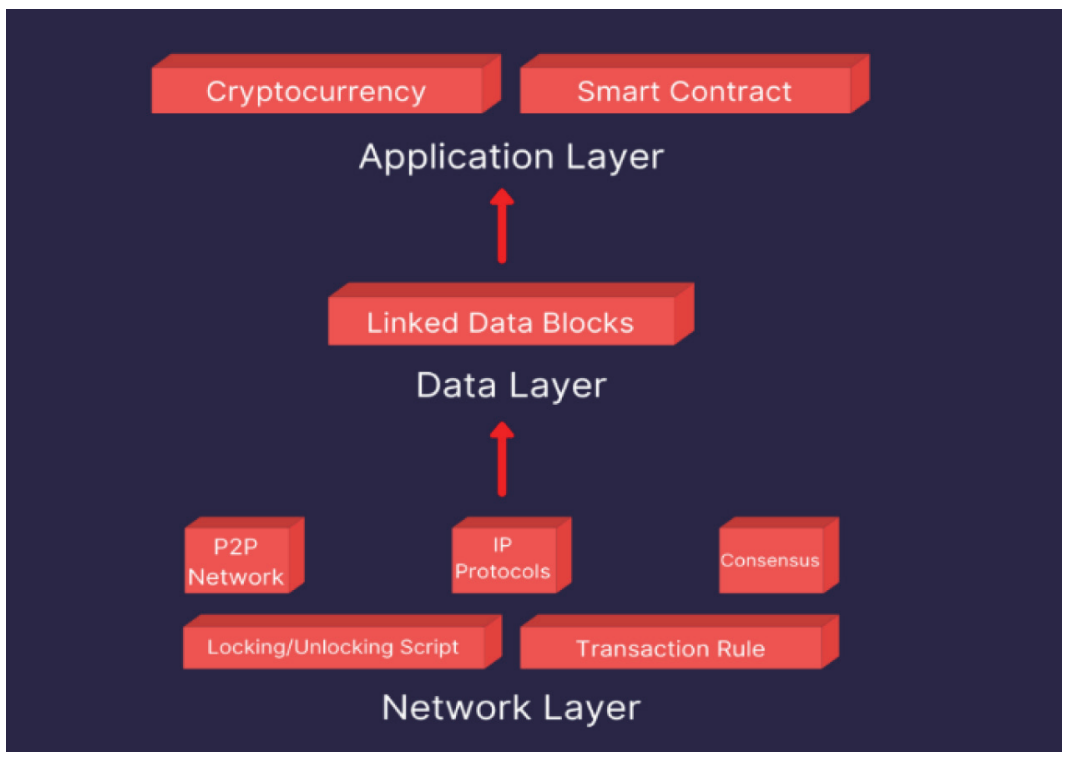

Figure 1: Blockchain in a Layered Network

Pervez Ahmad, Muhammad Ahmad, Usman Ahmed

Raza

A Review on Blockchain's Applications and Implementations
ADCAIJ: Advances in Distributed Computing and Artificial Intelligence Journal Regular Issue, Vol. 10 N. 2 (2021), 197-208 eISSN: 2255-2863 - https://adcaij.usal.es 


\section{Research Methodology}

The literature review of this paper has done such a process that it can be identified, analyzed, and derived results from research questions. Here are some of the techniques: Presenting researched questions, presenting learned materials, retrieving your desired data, sorting data obtained and clarifying the outcomes (Andrian et al., 2018).

Research questions are targeted and some questions are shown in the table below.

\begin{tabular}{|l|l|l|}
\hline ID & Research Questions & Motivation \\
\hline RQ-1 & $\begin{array}{l}\text { What is the Blockchain Technology } \\
\text { adopted by current applications }\end{array}$ & $\begin{array}{l}\text { Identifying the Blockchain technology and how to } \\
\text { develop applications using blockchain technology }\end{array}$ \\
\hline RQ-2 & $\begin{array}{l}\text { What are the applications implemented } \\
\text { using blockchain technology }\end{array}$ & $\begin{array}{l}\text { Identifying the verity of applications using } \\
\text { Blochian technology }\end{array}$ \\
\hline
\end{tabular}

In RQ-1 It will see how Blockchain Technology can be incorporated into current applications at the moment. Whether adding or not adding blockchain technology can make any difference.

In RQ-2 It will see how blockchain technology is being used in different applications. And how can benefit more with his help?

\section{The Blockchain Technology}

\subsection{Blockchain's Definition}

These days, Blockchain Technology is considered to be cryptocurrency such as Bitcoin, etc. But the reality is that Blockchain Technology is not implemented only in financial schemes because its definition says that it is a de-centralized (Figure 2) digital logbook which is mainly referred to keep the records of most significant things whether it is finance or any other operations.

These digital ledgers provide a safer user experience because they do not get corrupted \& no one can steal or intervene in them but our business layout can be changed and developed with the help of this technology.

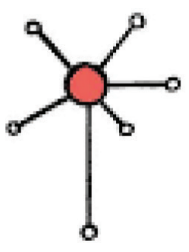

CENTRALIZED

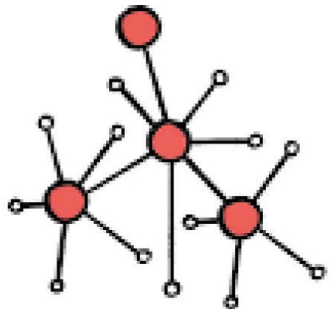

DECENTRALIZED

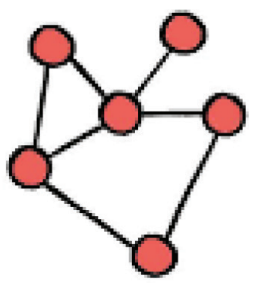

DISTRIQUTED

O none

Figure 2: Blockchain Defined as distributed Technology

Pervez Ahmad, Muhammad Ahmad, Usman Ahmed

Raza

A Review on Blockchain's Applications and Implementations
ADCAIJ: Advances in Distributed Computing and Artificial Intelligence Journal Regular Issue, Vol. 10 N. 2 (2021), 197-208 eISSN: 2255-2863 - https://adcaij.usal.es Ediciones Universidad de Salamanca - CC BY-NC-ND 


\subsection{Formation of The Blockchain Technology (BCT)}

Blockchain Technology is best described as a series of many blocks or nodes linked together which keep a record of all the transactions being made through this system. If there is a need to modify some of the transactions or make a new one, this will be verifying it at first which is done by a rearrangement in nodes and use many different methods for this purpose. The Blockchain, making the transaction forgery-resistant, never modifies or add any of the information without reaching the consensus (Gao et al., 2018).

\section{Scope of Blockchain Technology (BCT)}

Much study is being conducted on Blockchain Technology to discover more ways it can be implemented or used for society's benefits since the appearance of this. Its implementations are yet to be explored more but some of those are going to be debated here.

\subsection{Implementation in Finance}

Finance is the section where the Blockchain is being used mostly and largely and it starts with the emergence of Bitcoin which uses the Blockchain Technology to make the transactions direct and digital, eliminates the middlemen \& keeps a record of all the transactions in a digital ledger which is further used to trace any of the transactions (Tasatanattakool and Techapanupreeda, 2018). Blockchain Technology and Bitcoin cultivated many other cryptocurrencies in the whole world that's why the world trade in hundreds of cryptocurrencies these days (Aste et al., 2017).

Bitcoin (BTC). Bitcoin, achieved popularity and public interest being the ever first cryptocurrency to use the BCT. It also proved the security of the technology which makes it the world's most used cryptocurrency. But it comes with a disadvantage that its algorithm is proof-of-work which consumes much power when it adds a new block to the blockchain.

Ether (ETH). This cryptocurrency is reinforced by its own Ethereum Blockchain. It is the world's most used platform for Smart Contracts because it was the first-ever blockchain that initiated smart contracts. This cryptocurrency becomes more valuable because its blockchain technology possibly develops dApps to nourish the ecosystem of Ether. For the deployment of the dApps which are proficient in handling micropayments it comes with high rates which is also a problem for it (Valdeolmillos, et al., 2019).

Ripple (XRP). Ripple is supported by the Ripple blockchain and this currency is capable of handling 1,500 transactions within a second and it is also scalable and may be use a substitute option of payments. It uses Ripple Consensus Algorithm RPCA. The problem with this currency is that its blockchain is comparatively centralized than the others but the developers designed the Ripple mainly to help the banks which perform transactions internationally so this is not an actual problem (Valdeolmillos et al., 2019).

EOS. The blockchain of this cryptocurrency is of $3^{\text {rd }}$ generation which is costless, scalable, and also has the capability of deploying dApps in this. The consensus algorithm of the EOS is Delegated Proof-of-stake PoS. The delegated proof-of-stake is a substitute of PoS which makes the blocks of networks poll for the representative according to the stakes.

Tether (USDT) has alternative currency such as the dollar in the digital environment. Because it is a non-volatile currency, that's why it is considered a so-called stable currency. If the USDT organization

Pervez Ahmad, Muhammad Ahmad, Usman Ahmed

Raza

A Review on Blockchain's Applications and

Implementations
ADCAIJ: Advances in Distributed Computing and Artificial Intelligence Journal

Regular Issue, Vol. 10 N. 2 (2021), 197-208 eISSN: 2255-2863 - https://adcaij.usal.es Ediciones Universidad de Salamanca - CC BY-NC-ND 
and the dollar have to mutual trade then the company of tether (USDT) must have deposits of this worth or even more worth of dollars then they can be able to make mutual transactions. Tether works based on blockchain technology based on the protocols of the Omni layer. Because these protocols are used in blockchain technology, their functions are greatly increased. One of the advantages of this is without changing the baseline of blockchain technology we can expand the scope of Tether (Valdeolmillos et al., 2019).

\begin{tabular}{|l|l|l|l|l|l|}
\hline Cryptocurrency & $\begin{array}{l}\text { Consensus } \\
\text { algorithm }\end{array}$ & Scalability & $\begin{array}{l}\text { Smart } \\
\text { Contracts }\end{array}$ & $\begin{array}{l}\text { Transaction } \\
\text { count }\end{array}$ & $\begin{array}{l}\text { Active } \\
\text { addresses }\end{array}$ \\
\hline Bitcoin & PoW & No, $\sim 7$ TPS & $\begin{array}{l}\text { Non- } \\
\text { Turing- } \\
\text { Complete }\end{array}$ & $307.917 \mathrm{~K}$ & $636.805 \mathrm{~K}$ \\
\hline ETH & PoW & No, 7 TPS & $\begin{array}{l}\text { Turing- } \\
\text { Complete }\end{array}$ & $568.564 \mathrm{~K}$ & $242.449 \mathrm{~K}$ \\
\hline XRP & RPCA & $\sim 1500$ TPS & Not yet & $455.801 \mathrm{~K}$ & $5.986 \mathrm{~K}$ \\
\hline EOS & dPoS & Yes, $\sim 10 \mathrm{k}$ TPS & $\begin{array}{l}\text { Turing- } \\
\text { Complete }\end{array}$ & $6.33593 \mathrm{M}$ & $91.347 \mathrm{~K}$ \\
\hline Tether & $\begin{array}{l}\text { Omni Layer } \\
\text { protocol over } \\
\text { Bitcoin }\end{array}$ & $\begin{array}{l}\text { Yes, off-chain } \\
\text { scalability }\end{array}$ & Not yet & $20.244 \mathrm{~K}$ & $10.819 \mathrm{~K}$ \\
\hline
\end{tabular}

Figure 3: Comparison of cryptocurrencies

If you look at the figure 3 (Valdeolmillos et al., 2019), we will find that the market capitalization ranking of any currency depends on its current running leaves. But XPR is not included in this category because it has to be used by big organizations such as banks, rather than any individual user. The currencies which are based on PoW compatible algorithm are the same currencies that are more used in the market.

\subsection{Smart Contracts}

As shown from the title the middlemen and lawyers could easily be expelled out by Blockchain having smart contracts which all parties involving in the system can avail \& once it reaches consensus, any changes can be made. These contracts will be supportive to the businesses and private dealings also (Kaushik et al., 2017).

The studies were done in the past several years regarding the Smart Contracts emphases on the amalgamation of these with the other technologies for example with E-commerce and smart power microgrids as an author, for a decentralized trading system of power built on the Blockchain Technology, applied a PoC (Proof of concept) 528.Y Mazquita et al.

In which, both of the parties make their deals, set the price of energy, and securely complete their transaction. As additional securities, the author used encrypted messages and multi-signature. This system provides perfect decentralized trading systems for the trade of Smart Grid Energy and gives additional securities than a centralized system. Many of the countries are using BCT for their benefits such as Colombia uses the BCT to make transactions in their land rights processes by recording their

Pervez Ahmad, Muhammad Ahmad, Usman Ahmed

Raza

A Review on Blockchain's Applications and Implementations
ADCAIJ: Advances in Distributed Computing and Artificial Intelligence Journal Regular Issue, Vol. 10 N. 2 (2021), 197-208 elSSN: 2255-2863 - https://adcaij.usal.es Ediciones Universidad de Salamanca - CC BY-NC-ND 
transactions in the blockchainbased on Ethereum. Ukraine, Georgia \& Ghana, too, follow Colombia and Sweden in this regard. Unique identifiers are given to all the real estate properties stored in blockchain which afterward are accessible for the public and can be searched simply to find the owner of any of the assets (Mezquita et al., 2019).

\subsection{Internet of things (IoT) with Blockchain}

These days, the internet covers up a large portion of every person's life which is occasionally beyond our imaginations to understand how everything is connected. Many of the daily life devices such as smartphones and cameras even some of the "dumb items" for example smart toasters and fitness collars for dogs are linked with the web being a component of the Internet of Things (Gupta et al., 2018).

The term "Internet of Things (IoT)" is referred to a network of resources or devices as well as some sensors that are linked through the internet and share the necessary information among them just to provide us an easier lifestyle. Linked devices \& other gadgets in factories provide the capability for a fourth industrial revolution and it is predicted that more than half of new ventures will be running on the Internet of things (IoT) by 2021. The Internet of Things has undoubtfully made the surroundings smart and easier as well as they exposed us to vulnerabilities (Figure 4).

For example, living in a smart house having everything linked to each other through the internet and being tracked by each of the devices to get help would not be secure. Blockchain Technology provides a foolproof and decentralized industrial system associated with IoT.

\begin{tabular}{|c|c|c|}
\hline Challenge & Explanation & Potential blockchain solution \\
\hline $\begin{array}{l}\text { Costs and capacity } \\
\text { constraints }\end{array}$ & $\begin{array}{l}\text { It is a challenge to handle exponential } \\
\text { growth in loT devices: by } 2020 \text {, a network } \\
\text { capacity at least 1,000 times the level of } \\
2016 \text { will be needed. }\end{array}$ & $\begin{array}{l}\text { No need for a centralized entity: devices can } \\
\text { communicate securely, exchange value with each } \\
\text { other, and execute actions automatically through } \\
\text { smart contracts. }\end{array}$ \\
\hline $\begin{array}{l}\text { Deficient } \\
\text { architecture }\end{array}$ & $\begin{array}{l}\text { Each block of loT architecture acts as a } \\
\text { bottleneck or point of failure and disrupts } \\
\text { the entire network; vulnerability to } \\
\text { distributed denial-of-service attacks, hacking, } \\
\text { data theft, and remote hijacking also exists. }\end{array}$ & $\begin{array}{l}\text { Secure messaging between devices: the validity } \\
\text { of a device's identity is verified, and transactions } \\
\text { are signed and verified cryptographically to } \\
\text { ensure that only a message's originator could } \\
\text { have sent it. }\end{array}$ \\
\hline $\begin{array}{l}\text { Cloud server downtime } \\
\text { and unavailability of } \\
\text { services }\end{array}$ & $\begin{array}{l}\text { Cloud servers are sometimes down due to } \\
\text { cyberattacks, software bugs, power, cooling, } \\
\text { or other problems. }\end{array}$ & $\begin{array}{l}\text { No single point of failure: records are on many } \\
\text { computers and devices that hold identical } \\
\text { information. }\end{array}$ \\
\hline \multirow[t]{2}{*}{$\begin{array}{l}\text { Susceptibility to } \\
\text { manipulation }\end{array}$} & \multirow[t]{2}{*}{$\begin{array}{l}\text { Information is likely to be manipulated and } \\
\text { put to inappropriate uses. }\end{array}$} & $\begin{array}{l}\text { Decentralized access and immutability: malicious } \\
\text { actions can be detected and prevented. }\end{array}$ \\
\hline & & $\begin{array}{l}\text { Devices are interlocked: if one device's blockchain } \\
\text { updates are breached, the system rejects it. }\end{array}$ \\
\hline
\end{tabular}

Figure 4: The list of problems often met by the IoT \& that Blockchain can solve.

Pervez Ahmad, Muhammad Ahmad, Usman Ahmed

Raza

A Review on Blockchain's Applications and

Implementations
ADCAIJ: Advances in Distributed Computing and Artificial Intelligence Journal

Regular Issue, Vol. 10 N. 2 (2021), 197-208 eISSN: 2255-2863 - https://adcaij.usal.es Ediciones Universidad de Salamanca - CC BY-NC-ND 


\subsection{The Developing States and the Blockchain}

With the use of Blockchain in developing countries, the chances of corruption could be reduced or even eradicated because the transactions made through this technology are clear to people and having a record making it difficult to be modified that can be traced at any time. This type of clarity in transactions could secure the rights of the public and make the entire system reliable (Kshetri et al., 2018).

\subsection{The Communication}

The blockchain provides foolproof and high-value security that cannot be influenced or corrupted which have a great part in getting our communication network more secure and helps secure sensitive information being broadcasted by intelligence agencies or armies besides our daily conversations.

\subsection{Blockchain in Medical}

The Healthcare industries are very much attracted by Blockchain Technology as it is a sensitive field that requires reliability and efficiency (Kaushik et al., 2017). There is a dire need of tracking and storing the medical data obtained from patients and predicting medicines or possibilities of curing some disease based on that data where a small mistake can make the results lethal. With the help of Blockchain, the data can easily be available to use without getting it mixed.

\subsection{The Blockchain and the Artificial Intelligence (AI)}

Artificial Intelligence (AI) has become a hyped market with vendors, media, and clients all discussing eagerly the competencies of AI. Similarly, the Blockchain is also said to be capable of doing things digitally.

This is not only hype but they both have paved the way for innovations these days. Their convergence is unavoidable because they both contract with value and data and it can improve Machine Learning and enable the artificial intelligence to create and trade financial products as the blockchain has strong suggestions for financial transactions \& sharing important data between institutions whereas AI involves computers to do many things where human intelligence is needed by analyzing, classifying and making predictions from the given data (Dinh et al., 2018).

The data is central to Artificial Intelligence efficiency and the Blockchain offers combined \& secured sharing of data (Figure 5). The Blockchain could guarantee the reliability of data \& can allow more data to get shared safely before Artificial Intelligence extracts results from it because its data is publicly available and include all record which makes Artificial Intelligence fewer threatening (Dinh et al., 2018).

In return, Artificial Intelligence helps the process being done by the Blockchain by automating and optimizing it for a great presentation. The AI can also help in secure the secrecy of users as the data in Blockchain is publicly available.

Pervez Ahmad, Muhammad Ahmad, Usman Ahmed

Raza

A Review on Blockchain's Applications and

Implementations
ADCAIJ: Advances in Distributed Computing and Artificial Intelligence Journal Regular Issue, Vol. 10 N. 2 (2021), 197-208 elSSN: 2255-2863 - https://adcaij.usal.es Ediciones Universidad de Salamanca - CC BY-NC-ND 


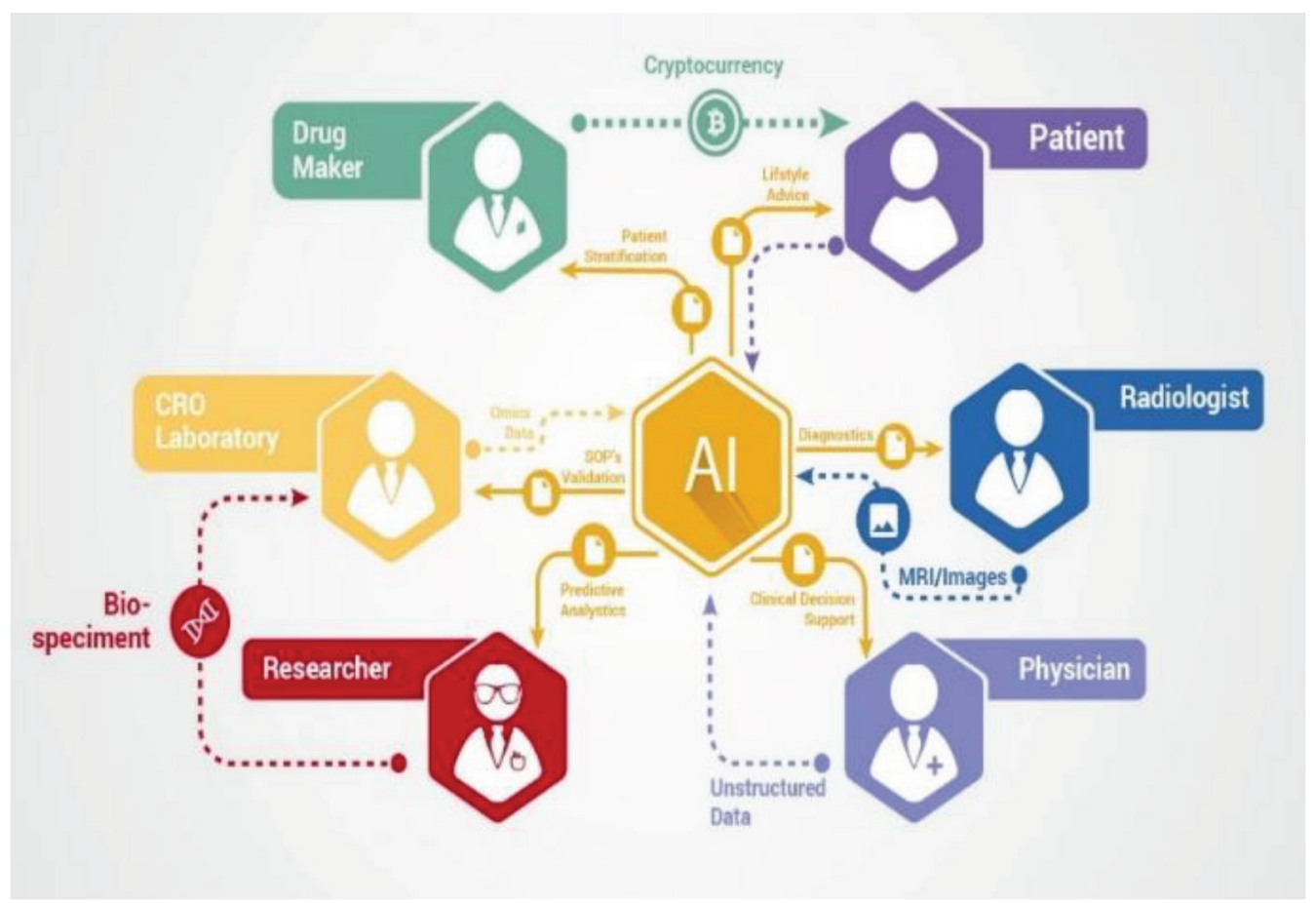

Figure 5: Artificial Intelligence with Blockchain

\section{Fears Regarding Blockchain}

Even though Blockchain Technology is offering lots of things to the users and can bring more valuable innovations to the world's multiple systems, it has also got some problems or fears to be overcome. The said technology is a new one in the market with more and more discoveries appearing as the research goes with it. Some of the main doubts regarding the Blockchain areas under (Kaushik et al., 2017).

\section{Conclusion}

This survey paper tells us that what is Blockchain Technology \& how helps implement \& integrate with the other technologies in strengthening multiple segments. There is a need for loads of studies for exploring the entire capability of this technology \& possible implementations regarding the Blockchain. There is a dire need to further explore this technology right now because there are many things that need to be clear as described in (Figure 6). Because as modern as this technology, its misuse can leave a huge impact on people to make this technology popular, its effective use is very important. If this technology is not made clearer on this occasion, people will not be able to recognize its utility 


\begin{tabular}{|c|l|}
\hline Concerns & \multicolumn{1}{|c|}{ Expectations } \\
\hline Security & $\begin{array}{l}\text { Majority Attack: Majority attacks can be performed when } \\
\text { controlling more than 50\% of Miners in the blockchain. In this } \\
\text { case, the entire process of writing blocks to the chain can be } \\
\text { hijacked, and potentially erroneous blocks can be introduced. } \\
\text { Selfish Mining: In selfish mining, the attackers put mined } \\
\text { blocks in a private branch instead of broadcasting them. The } \\
\text { private branch is then revealed to the public only when it is } \\
\text { longer than the public chain, increasing the mining rewards to } \\
\text { the attacker to the detriment of the miners from the original } \\
\text { public chain. }\end{array}$ \\
\hline $\begin{array}{c}\text { Anonymity and } \\
\text { Privacy }\end{array}$ & $\begin{array}{l}\text { Blockchain allows its users to make transactions } \\
\text { anonymously, Nonetheless, because the transactions are } \\
\text { public, they may still the traceable clues that can reveal the } \\
\text { identity and private information of the user. }\end{array}$ \\
\hline Abuse of Blockchain & $\begin{array}{l}\text { The Use of cryptographically secure systems provide security } \\
\text { for both benign and criminal users alike }\end{array}$ \\
\hline
\end{tabular}

Figure 6: Fears regarding Blockchain Technology

properly due to which it can be controversial only when a new technology starts. To the new researching people, I would only suggest that they do more research on their procedures.

\section{Funding}

This study got no funds from any government/Private organization.

\section{Conflict of Interest}

The authors declare that they have no conflict of interest.

\section{Acknowledgement}

I am very glad to say that during the research, Sir Usman Raza who guided us all the time with such sincerity and dedication is highly commendable.

Pervez Ahmad, Muhammad Ahmad, Usman Ahmed

Raza

A Review on Blockchain's Applications and Implementations
ADCAIJ: Advances in Distributed Computing and Artificial Intelligence Journal Regular Issue, Vol. 10 N. 2 (2021), 197-208 elSSN: 2255-2863 - https://adcaij.usal.es Ediciones Universidad de Salamanca - CC BY-NC-ND 


\section{References}

Andrian, H. R., Kurniawan, Suhardi, N. B. (2018, October). "Blockchain Technology and Implementation: A Systematic Literature Review.” International Conference on Information Technology Systems and Innovation (ICITSI). (pp. 370-374). IEEE, 2018.

Antonucci, F., Figorilli, S., Costa, C., Pallottino, F., Raso, L., \& Menesatti, P. (November de 2019). A review on blockchain applications in the agri-food sector. Journal of the Science of Fodd and Agriculture, 99(14), 6129-6138. doi:10.1002/jsfa.9912

Aste, T., Paolo Tasca, and Matteo T. D. (2017). "Blockchain technologies: The foreseeable impact on society and industry." computer 50(9), 18-28.

Atzori, M. (1 de December de 2015). Blockchain Technology and Decentralized Governance: Is the State Still Necessary? doi:10.2139/ssrn.2709713

Bayer, D., Haber, S., \& Sornetta, W. S. (1993). Improving the Efficiency and Reliability of Digital Time-Stamping. En R. Capocelli, A. De Santis, \& U. Vaccaro (Ed.), Sequences II - Methods in Communication, Security, and Computer Science (págs. 329-334). New York: Springer-Verlag New York. doi: https://doi.org/10.1007/978-1-4613-9323-8_24

Cong, L. W., \& He, Z. (4 de April de 2019). Blockchain Disruption and Smart Contracts. The Review of Financial Studies, 32(5), 1754-1797. doi:10.1093/rfs/hhz007

Crosby, M., Nachiappan, Pattanayak, P., Verma, S., \& Kalyanaraman, V. (June de 2016). BlockChain Technology: Beyond Bitcoin. AIR Applied Innovation Review (2).

Dai, H. N., Zheng, Z. and Zhang, Y., (2019). Blockchain for Internet of Things: A survey. IEEE Internet of Things Journal, 6(5), pp.8076-8094.

Dinh, T. N., and Thai, M. T. (2018). "Ai and blockchain: A disruptive integration." Computer, 51(9), $48-53$

Dorri, A., Kanhere, S. S., \& Jurdak, R. (2017, April). Towards an optimized blockchain for IoT. In 2017IEEE/ACM Second International Conference on Internet-of-Things Design and Implementation (IoTDI) (pp. 173-178). IEEE.

Fan, L., \& Zhou, H. S. (2017). A scalableproof-of-stake blockchain in the open setting (or, how to mimic nakamoto's design viaproof-of-stake). Cryptology ePrint Archive, Report 2017/656.

Fanning, K., and David P. Centers (2016). "Blockchain and its coming impact on financial services." Journal of Corporate Accounting \& Finance 27(5), 53-57.

Fernández-Caramés, T. M., \& Fraga-Lamas, P. (6 de July de 2018). A Review on the Use of Blockchain for the Internet of Things. IEEE Access, 6, 32979-33001.

Ferrer, E. C. (2018). "The blockchain: a new framework for robotic swarm systems." In Proceedings of the future technologies conference, pp. 1037-1058. Springer, Cham.

Gao, Weichao, William G. Hatcher, and Wei Yu. (July 2018). "A survey of blockchain: Techniques, applications, and challenges." $27^{\text {th }}$ international conference on computer communication and networks (ICCCN). IEEE.

Gupta, Y., Rajeev Shorey R., Kulkarni, D., and Tew, J. (2018). "The applicability of blockchain in the Internet of Things." In 2018 10th International Conference on Communication Systems \& Networks (COMSNETS), pp. 561-564. IEEE, 2018.

Haber, S., \& Stornetta, W. S. (January de 1991). How to Time-Stamp a Digital Document. Journal of Cryptology (3), 99-111. doi:10.1007/BF00196791

Pervez Ahmad, Muhammad Ahmad, Usman Ahmed

Raza

A Review on Blockchain's Applications and

Implementations
ADCAIJ: Advances in Distributed Computing and Artificial Intelligence Journal

Regular Issue, Vol. 10 N. 2 (2021), 197-208 elSSN: 2255-2863 - https://adcaij.usal.es Ediciones Universidad de Salamanca - CC BY-NC-ND 
Kaushik, A., Choudhary, A., Ektare, C., Thomas, D., \& Akram, S. (2017, May). Blockchain-literature survey. In 2017 2nd IEEE International Conference on Recent Trends in Electronics, Information \& Communication Technology (RTEICT) (pp. 2145-2148). IEEE.

Kshetri, N. and Voas, J. (2018). "Blockchain in Developing Countries," in IT Professional, 20.2, pp. 11-14.

Lamport, L., Shostak, R. E., \& Pease III, M. C. (July de 1982). The Byzantine Generals Problem. ACM Transactions on Programming Languages and Systems, 4(3), 387-389. doi:10.1145/357172.357176

Li, X., Jiang, P., Chen, T., Luo, X., \& Wen, Q. (2020). "A survey on the security of blockchain systems." Future Generation Computer Systems 107 (2020): 841-853.

Mezquita, Y., Casado-Vara, R., González Briones, A., Prieto, J., \& Corchado, J. M. (2020) “Blockchainbased architecture for the control of logistics activities: Pharmaceutical utilities case study." Logic Journal of the IGPL.

Mezquita, Y., Valdeolmillos, D., González-Briones, A., Prieto, J., \& Corchado, J. M. (2019, July). "Legal aspects and emerging risks in the use of smart contracts based on blockchain." International Conference on Knowledge Management in Organizations. (pp. 525-535). Springer, Cham.

Motta, G. A., Tekinerdogan B., \& Athanasiadis, I. N. (21 de February de 2020). Blockchain Applications in the Agri-Food Domain: The First Wave. Frontiers in Blockchain, 3, 1-13. doi:10.3389/ fbloc.2020.00006

Nofer, M., Gomber, P., Hinz, O. \& Schiereck, D. (2017). "Blockchain.” Business \& Information Systems Engineering 59(3), 183-187.

Nakamoto, S. (2008). Bitcoin: A Peer-to-Peer Electronic Cash System. Recuperado el 28 de 11 de 2020, de Bitcoin Project: https://bitcoin.org/bitcoin.pdf

Nascimento, S. F., Póvora, A. R., Anderberg, A., Elena, A., Bellia, M., Cales, L., Spirito, L. (2019). Blockchain Now and Tomorrow - Assessing Multidimensional impacts of Distributed Ledger Technologies. European Union, Joint Research Centre. Luxembourg: Publications Office of the European Union. doi:10.2760/901029

Pilkington, M. (2016). Blockchain technology: principles and applications. In Research handbook on digital transformations. Edward Elgar Publishing.

Rauchs, M., Glidden, A., Grdon, B., Pieters, G. C., Recanatini, M., Rostand, F., Zhang, B. Z. (13 de August de 2018). Distributed Ledger Technology Systems: A Conceptual Framework. 97. doi:10.2139/ ssrn. 3230013

Samaniego, M., Jamsrandorj, U., \& Deters, R. (2016, December). "Blockchain as a Service for IoT." 2016 IEEE international conference on internet of things (iThings) and IEEE green computing and communications (GreenCom) and IEEE cyber, physical and social computing (CPSCom) and IEEE smart data (SmartData). (pp. 433-436). IEEE.

Tapscott, D., \& Tapscott, A. (2017). "How blockchain will change organizations.” MIT Sloan Management Review 58(2), 10.

Tapscott, D., \& Tapscott, A. (2019). Blockchain Revolution: How the Technology Behind Bitcoin and Other Cryptocurrencies Is Changing Money. London: Penguin Business.

Tasatanattakool, P., and Techapanupreeda, C. (2018, January) "Blockchain: Challenges and applications." In 2018 International Conference on Information Networking (ICOIN),, (pp. 473-475). IEEE, 2018.

Pervez Ahmad, Muhammad Ahmad, Usman Ahmed

Raza

A Review on Blockchain's Applications and

Implementations
ADCAIJ: Advances in Distributed Computing and Artificial Intelligence Journal

Regular Issue, Vol. 10 N. 2 (2021), 197-208 eISSN: 2255-2863 - https://adcaij.usal.es Ediciones Universidad de Salamanca - CC BY-NC-ND 
Valdeolmillos, D., Mezquita, Y., González-Briones, A., Prieto, J., \& Corchado, J. M. (2019, June). "Blockchain technology: a review of the current challenges of cryptocurrency." International Congress on Blockchain and Applications. (pp. 153-160). Springer, Cham.

Xiong, H., Dalhaus, T., Wang, P., \& Huang, J. (2 de February de 2020). Blockchain Technology for Agriculture: Applications and Rationale. Frontiers in Blockchain, 3, 1-7. doi:10.3389/ fbloc.2020.00007

Yaga, D., Mell, P., Roby, N. and Scarfone, K. (2019). Blockchain technology overview. arXiv preprint arXiv:1906.11078.

Zhao, G., Liu, S., Lopez, C., Lu, H., Elgueta, S., Chen, H., \& Boshkoska, B. M. (August de 2019). Blockchain technology in agri-food value chain management: A synthesis of applications, challenges and future research directions. Computers in Industry, 109, Pages 83-99. doi:10.1016/j. compind.2019.04.002

Zheng, Z., Xie, S., Dai, H.-N., Chen, X., \& Wang, H. (13 de 10 de 2018). Blockchain challenges and opportunities: a survey. International Journal of Web and Grid Services (IJWGS), 14(4), 352-375. doi:10.1504/IJWGS.2018.095647 